\title{
A Case of Central Precocious Puberty Due to Concomitant Hypothalamic Hamartoma and Juvenile Pilocytic Astrocytoma
}

\author{
Gönül Çatlı1, Ayhan Abacı1, Ahmet Anık1, Handan Güleryüz2, Erdener Özer3, Irfan Öcal4, \\ Nurullah Yüceer5, Kamer Mutafoğlu6 \\ ${ }^{1}$ Dokuz Eylül University Faculty of Medicine, Department of Pediatric Endocrinology, Izmir, Turkey \\ 2Dokuz Eylül University Faculty of Medicine, Department of Radiology, Izmir, Turkey \\ ${ }^{3}$ Dokuz Eylül University Faculty of Medicine, Department of Pathology, Izmir, Turkey \\ 4 Izmir Atatürk Training Research and Hospital, Department of Pathology, Izmir, Turkey \\ ${ }^{5}$ Dokuz Eylül University Faculty of Medicine, Department of Neurosurgery, Izmir, Turkey \\ ${ }^{6}$ Dokuz Eylül University Faculty of Medicine, Department of Pediatric Oncology, Izmir, Turkey
}

\begin{abstract}
Central precocious puberty (CPP) is caused by premature activation of the hypothalamo-pituitary-gonadal axis. More than $50 \%$ of boys with CPP have an identifiable etiology. Hypothalamic hamartoma $(\mathrm{HH})$, hydrocephalus, tumors, infections, congenital defects, ischemia, radiation, or injury of the brain are the most common causes of secondary CPP. In this report, we present the case of a 2 years and 9 months old male patient who had a $30 \times 40 \mathrm{~mm}$ contrast-enhancing suprasellar mass and was histopathologically diagnosed with giant $\mathrm{HH}$. However, since $\mathrm{HHs}$ are designated as non-enhancing masses, considering the possibility of an incomplete diagnosis of a glial tumor, the patient was followed up. Clinical and radiological follow-up revealed stable findings with no evidence of tumor growth until the third year after surgery when he presented with neurological deficit due to the rapid growth of the suprasellar mass. After the second surgery, histopathological examination of the biopsy specimen revealed the lesion to be a juvenile pilocytic astrocytoma (PA). The concomitance of $\mathrm{HH}$ and juvenile PA is very rare. To our knowledge, this is the first report of a patient with concomitant juvenile PA and HH who developed CPP and did not have gelastic epilepsy despite the rapidly growing giant mass.

Key words: Hypothalamic hamartoma, pilocytic astrocytoma, central precocious puberty
\end{abstract}

Conflict of interest: None declared

Received: 12.02 .2014

Accepted: 30.04 .2014

\section{Introduction}

Central precocious puberty (CPP) or gonadotropin-releasing hormone-dependent precocious puberty, which is caused by premature activation of the hypothalamo-pituitary-gonadal axis is more common in girls than in boys (1). Approximately $95 \%$ of girls with CPP have idiopathic CPP and only $5 \%$ have an underlying central nervous system (CNS) disorder. On the other hand, more than $50 \%$ of boys with CPP have an identifiable etiology and idiopathic CPP is a diagnosis of exclusion (2). Therefore, CNS disease needs to be ruled out before reaching a diagnosis of idiopathic precocious puberty in a male patient. Tumors (optic glioma, astrocytoma, ependymoma, medulloblastoma), infections, congenital defects, cerebral ischemia and radiation or injury to the CNS can all lead to secondary CPP (2). The most common underlying defects are hypothalamic hamartoma $(\mathrm{HH})$ and hydrocephalus (1). The reported incidence of $\mathrm{HH}$ in patients with precocious puberty varies from $14 \%$ to $58 \%$ (3). Juvenile pilocytic astrocytomas (PA) are low-grade CNS tumors which, have a low growth potential and have been reported to regress spontaneously without malignant changes $(4,5)$. Concomitance of $\mathrm{HH}$ with juvenile $\mathrm{PA}$ is very rare.

In this report, we present the case of a patient with concomitant $\mathrm{HH}$ and juvenile PA who developed CPP within the second year of clinical follow-up and who showed no epileptic symptoms despite the giant mass.

Address for Correspondence

Ayhan Abacı MD, Dokuz Eylül University Faculty of Medicine, Department of Pediatric Endocrinology, Izmir, Turkey

Phone: +90 2324126076 E-mail: ayhanabaci@gmail.com

OJournal of Clinical Research in Pediatric Endocrinology, Published by Galenos Publishing. 


\section{Case Report}

A 29/12 years old male patient had been admitted to the emergency department with complaints of headache, vomiting and gait disorder which had developed within the past month. In brain magnetic resonance imaging (MRI), a lobulated contoured and contrast-enhancing suprasellar mass was detected. The mass was $30 \times 40 \mathrm{~mm}$ in size, consisted of solid and cystic components and had led to hydrocephalus (Figure 1). After incomplete surgical resection of the tumor, the histopathological findings were reported to be compatible with neuronal hamartoma (Figure 2).

The patient was referred to the pediatric endocrinology clinic for evaluation of probable anterior and posterior pituitary hormone deficiencies. On physical examination, his weight was $16 \mathrm{~kg}$ (75-90p) [+1.28 standard deviation score (SDS)] and height was $98 \mathrm{~cm}$ (90-95p) (+1.36 SDS). Clinical findings were normal and puberty was compatible with Tanner stage 1. Determination of hormone levels in a morning plasma specimen revealed an adrenocorticotropic hormone level of $46 \mathrm{pg} / \mathrm{mL}$ (normal, 0-46), a serum cortisol level of $19.7 \mu \mathrm{g} / \mathrm{dL}$ (normal, 0.8-1.9), a prolactin level of $3.19 \mathrm{ng} / \mathrm{mL}$ (normal, 2.5-17). Thyroid-stimulating hormone level was $3.98 \mathrm{mlU} / \mathrm{mL}$ (normal, 0.4-5) and free thyroxine level was $1.05 \mathrm{ng} / \mathrm{dL}$ (normal, 0.8-1.9). In view of the location of the mass, it was decided that the patient needed to be followed up for the possible development of hypothalamo-pituitary disorders such as CPP and growth failure. He was also being followed up clinically and radiologically for his giant intracranial mass.

At the age of five years and six months, the patients' weight was $23 \mathrm{~kg}$ (75-90p) (+1.23 SDS), his height was $116 \mathrm{~cm}$ (75-90p) (+0.98 SDS) and his testicular volumes were $5 \mathrm{~mL}$ and $6 \mathrm{~mL}$. He had no pubic hair. During the physical examination, aggressive behavior and mental retardation were noted. However, he had no history of any type of epilepsy. Biochemical measurements revealed a basal follicle-stimulating hormone level of 2.48 $\mathrm{mIU} / \mathrm{mL}$ (normal, 0.7-11.1), luteinizing hormone (LH) level of $1.45 \mathrm{mlU} / \mathrm{mL}$ (normal, 0.8-7.6) and a total testosterone level of 50 ng/dL (normal, 3-30). Scrotal USG revealed age-inappropriate enlargement of the testicles with normal echotexture - the right testicle was $22 \times 15 \times 35 \mathrm{~mm}$ and the left testicle was $21 \times 16 \times 34 \mathrm{~mm}$ in diameter. The bone age was compatible with the chronological age. In LH-releasing hormone test, a peak LH value of $15 \mathrm{mlU} / \mathrm{mL}$ $(>5)$ was detected by direct chemiluminometric technique. The patient was diagnosed with CPP and started on gonadotropinreleasing hormone $(\mathrm{GnRH})$ agonist treatment (triptorelin acetate $3.75 \mathrm{mg}$ every 4 weeks). A normal electroencephalogram ruled out subclinical epileptic activity. Until the third year after the surgery, the patient was clinically and radiologically stable with no evidence of tumor growth. However, at the age of six years and three months, the patient was referred with neurological deficit due to the rapid growth of the suprasellar mass. After the second surgery, he died because of brain herniation. Histopathological examination of the biopsy specimen revealed the lesion to be a juvenile PA (Figure 3).

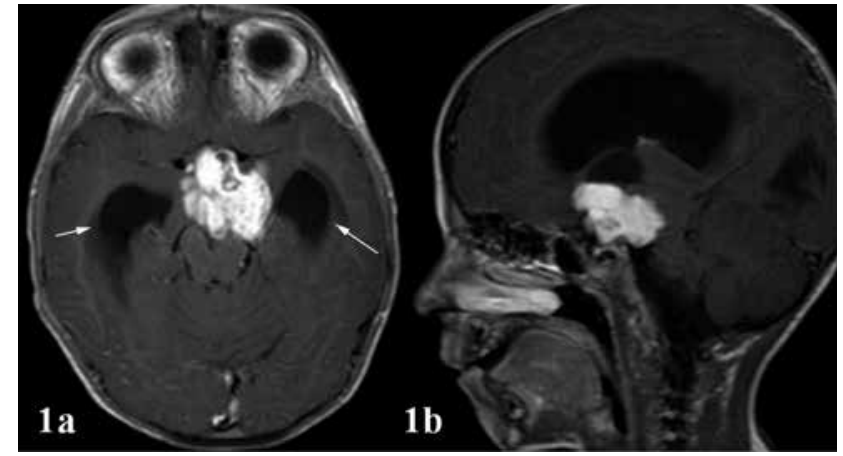

Figure 1. In the T1-weighted axial (a) and sagittal (b) sections a contrastenhancing suprasellar mass with solid and cystic components is shown. Hydrocephalus is present due to compression by the mass (arrows)

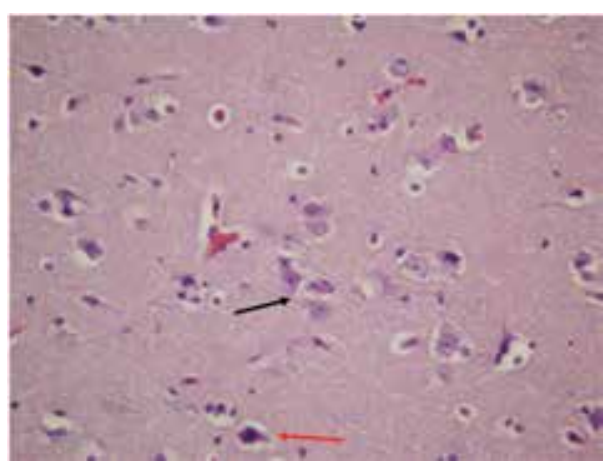

Figure 2. Histological examination disclosed single or clustered hamartomatous neuronal cells (black arrows) as well as reactive astrocytes (red arrow) (H\&E, x200)

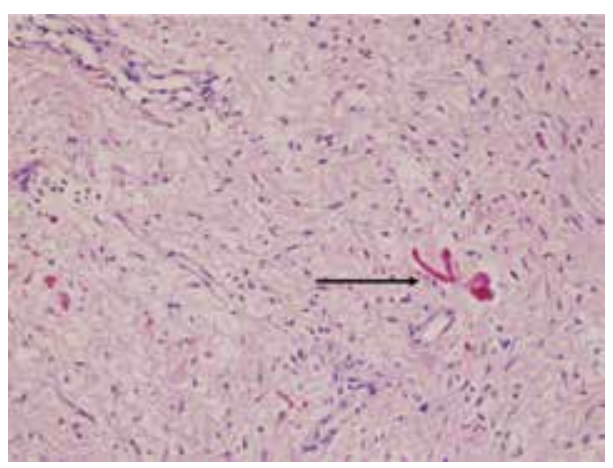

Figure 3. Diffuse astrocytoma predominantly composed of piloid cells and Rosenthal fibers (black arrows) in piloid areas (H\&E, X200)

\section{Discussion}

$\mathrm{HHs}$ are rare (1:200 000) heterotopic congenital intracranial malformations with a mean diameter of 17.9-18 mm. They consist of benign neural and glial cells and usually originate from tuber cinereum, mamillary bodies and posterior hypothalamus $(6,7,8)$. HHs are divided into two groups according to their MRI findings: i) parahypothalamic (pedunculated) type which is 
Çatı $\mathrm{G}$ et al.

Precocious Puberty, Hamartoma and Astrocytoma

generally related to CPP and ii) $\mathrm{HHs}$ (intrahypothalamic) which are usually associated with epileptic activities (9). The most frequently reported clinical findings in $\mathrm{HH}$ are CPP (63\%), gelastic epilepsy $(61 \%)$ and in $23 \%$ of cases, a combination of CPP and gelastic epilepsy (6). In a review of MRI findings and clinical features, 8 out of 10 patients with $\mathrm{HH}$ were found to have developed CPP before the age of 3 years (2). The current patient presented with neurological symptoms due to a suprasellar mass, which was initially diagnosed as giant $\mathrm{HH}$ according to the histopathological examination results. Two years after incomplete resection of the mass, when he was 5.5 years old, CPP developed.

The treatment of choice in $\mathrm{HH}$ is surgical; however, due to adhesion and invasion to the adjacent structures, it cannot be usually removed completely. In HH cases with intractable epilepsy and mass-related clinical findings, while surgical resection is recommended, wide resections must be avoided to prevent the development of neurologic sequelae $(6,10)$. In cases without neurological findings, non-invasive treatment methods such as radiofrequency ablation and radio-surgical treatment are also recommended (6). Most cases with $\mathrm{HH}$-related CPP respond well to the $\mathrm{GnRH}$ analog treatment. In the present case, because of presence of neurological findings, surgical intervention was performed, but the mass could not be removed completely. $\mathrm{GnRH}$ analog treatment was given for the CPP and progression of puberty was clinically and biochemically restrained with this treatment.

PA is the most common benign brain tumor in childhood. It usually arises within the cerebellum and rarely in the hypothalamic/ chiasmatic region, but it may occur in any area where astrocytes are present $(11,12,13,14)$. PAs are often cystic and characteristically contrast-enhancing tumors in computed tomography and MRI studies (15). The prognosis for children with PA is generally good and the 20-year survival rate is approximately $70 \%-80 \%$ even after undergoing subtotal resection (13). However, malignant transformation, leptomeningeal seeding or recurrence can also be encountered in these tumors $(11,16)$. There is no report documenting spontaneous malignant transformation of a WHO grade 1 PA. A review of the literature showed that individuals who suffered malignant transformation all had tumors that had been previously irradiated (4).

CPP due to astrocytoma has been reported previously (17). The current patient had a $30 \times 40 \mathrm{~mm}$ contrast-enhancing suprasellar mass, which consisted of solid and cystic components and caused hydrocephalus demonstrated on brain MRI. After incomplete surgical resection of the tumor, based on histopathological findings, he was initially diagnosed with giant $\mathrm{HH}$. However, since $\mathrm{HH}$ are designated as non-enhancing masses (15), considering the possibility of an incomplete diagnosis of a glial tumor, the patient underwent clinical and radiological follow-up which revealed stable findings with no evidence of tumor growth until the third year after the surgery. However, at the age of six years and three months, he presented with neurological deficit due to the rapid growth of the suprasellar mass. After the second surgery, histopathological examination of the biopsy specimen revealed the lesion to be a juvenile PA. We suggest that in this patient, the limited resection of the mass in the first surgical intervention may have led to an incomplete diagnosis. Juvenile PA and $\mathrm{HH}$ are pathologically quite different lesions. However, they behave similarly in that neither tends to show spontaneous malignant transformation and even large PAs have been shown to regress without treatment $(4,18)$. However, a small subset of children with this tumor experience a poor clinical course with shorter disease-free survival and higher mortality rates. Although it has long been recognized that particular PAs behave aggressively, the reasons for this have not yet been elucidated (13).

Previously, Park et al (19) have reported a 6-year-old girl presenting with intractable gelastic seizures with a spontaneously regressing juvenile PA and a concomitant $\mathrm{HH}$. To our knowledge, this is the second report of a patient with concomitant juvenile PA and $\mathrm{HH}$. Distinct from the previous report, our patient developed CPP and despite the rapidly growing giant mass he did not have gelastic epilepsy.

In conclusion, although $\mathrm{HH}$ is the most frequent organic cause of CPP, in a patient with a hypothalamic mass, the presence of pathological contrast enhancement in MRI should alert the physician to consider a diagnosis other than $\mathrm{HH}$, particularly a glial tumor. With this case report, we would like to emphasize that although rare, $\mathrm{HH}$ and juvenile PA may occur concurrently in a patient.

\section{References}

1. Fahmy JL, Kaminsky CK, Kaufman F, Nelson MD Jr, Parisi MT. The radiological approach to precocious puberty. $\mathrm{Br} \mathrm{J}$ Radiol 2000;73:560-567.

2. Faizah $M Z$, Zuhanis $A H$, Rahmah $R$, Raja $A A, W u L L$, Dayang AA, Zulfiqar MA. Precocious puberty in children: A review of imaging findings. Biomed Imaging Interv J 2012;8:6.

3. Ng SM, Kumar Y, Cody D, Smith CS, Didi M. Cranial MRI scans are indicated in all girls with central precocious puberty. Arch Dis Child 2003;88:414-418.

4. Parsa CF, Givrad S. Juvenile pilocytic astrocytomas do not undergo spontaneous malignant transformation: grounds for designation as hamartomas. Br J Ophthalmol 2008;92:40-46. Epub 2007 Oct 25

5. Rozen WM, Joseph S, Lo PA. Spontaneous regression of lowgrade gliomas in pediatric patients without neurofibromatosis. Pediatr Neurosurg 2008;44:324-328. Epub 2008 May 27

6. Alves C, Barbosa V, Machado M. Giant hypothalamic hamartoma: case report and literature review. Childs Nerv Syst 2013;29:513516. Epub 2013 Jan 13

7. Berkovic SF, Kuzniecky RI, Andermann F. Human epileptogenesis and hypothalamic hamartomas: new lessons from an experiment of nature. Epilepsia 1997;38:1-3.

8. Dorfer C, Kasprian G, Mühlebner A, Czech T.Giant solid-cystic hypothalamic hamartoma. Case report. Neurosurg Focus 2011;30:7

9. Miranda P, Esparza J, Cabrera A, Hinojosa J. Giant hypothalamic hamartoma operated through subfrontal approach with orbitary rim osteotomy. Pediatr Neurosurg 2006;42:254-257. 
Çatı G et al

Precocious Puberty, Hamartoma and Astrocytoma

10. Ng YT, Rekate HL. Successful third surgery for a case of status gelasticus: lessons learned after nearly 200 cases of hypothalamic hamartoma surgical resection. Epilepsia 2011;52:1-3.

11. Austin EJ, Alvord EC Jr. Recurrences of cerebellar astrocytomas: a violation of Collins' law. J Neurosurg 1988:68:41-47.

12. Perilongo G, Carollo C, Salviati L, Murgia A, Pillon $M$, Basso G, Gardiman M, Laverda A. Diencephalic syndrome and disseminated juvenile pilocytic astrocytomas of the hypothalamic-optic chiasm region. Cancer 1997;80:142-146.

13. Bruce JN, Zacharia BE, Mocco J, Sughrue ME, Sisti AC, Komotar RJ. Pilomyxoid astrocytoma: a review. MedGenMed 2004;6:42.

14. Komotar RJ, Burger PC, Carson BS, Brem H, Olivi A, Goldthwaite PT, Tihan T. Pilocytic and pilomyxoid hypothalamic/chiasmatic astrocytomas. Neurosurgery 2004;54:72-79.
15. Burger PCSB. Atlas of tumor pathology. Tumors of the central nervous system. Armed Forces Institute of Pathology, Washington, DC. 1994.

16. Auer RN, Rice GP, Hinton GG, Amacher AL, Gilbert JJ. Cerebellar astrocytoma with benign histology and malignant clinical course. Case report. J Neurosurg 1981;54:128-132.

17. Chemaitilly W, Trivin C, Adan L, Gall V, Sainte-Rose C, Brauner R. Central precocious puberty: clinical and laboratory features. Clin Endocrinol (Oxf) 2001;54:289-294.

18. Schmandt SM, Packer RJ, Vezina LG, Jane J. Spontaneous regression of low-grade astrocytomas in childhood. Pediatr Neurosurg 2000; 32:132-136.

19. Park YS, Lee YH, Shim KW, Kim DS, Lee JS, Kim HD. Endoscopic disconnection of hypothalamic astrocytoma causing gelastic epilepsy. Case report. J Neurosurg Pediatr 2009;4:151-155. 